\title{
Judgement, taste and closely related Germanic languages
}

\author{
Robin Cooper
}

\begin{abstract}
We will look at a treatment of the semantics of taste predicates using TTR (Type Theory with Records). The central idea is that we take the notion of judgement from type theory as basic and derive a notion of truth from that, rather than starting from a semantics based on a notion of truth and trying to modify it to include a notion of judgement. Our analysis involves two types of propositions: Austinian propositions, whose components include a situation and a type, and a subtype of Austinian propositions called subjective Austinian propositions, whose components in addition include an agent who makes the judgement that the situation is of the type. We will argue that attitude verbs can select either for propositions in general (subjective or objective) or for subjective propositions, but that there is no type of objective propositions which can be selected for. We will discuss some apparent counterexamples to this from Germanic languages and argue that there is a phenomenon akin to switch reference in certain attitude predicates when their complement involves a subjective proposition.
\end{abstract}

\section{Introduction}

The classical view of meaning in model-theoretic semantics is based on the notion of truth in a possible world conceived of as one way the universe could be. While truth is of central importance in semantics, the notion of truth in a possible world characterizing total information about the whole universe seems an unlikely foundation for the kind of natural reasoning that humans engage in as they wander about the actual world gathering partial information about it. Equally unlikely, it seems to me, would be a view that human reasoning is defined in terms of proof-theoretic manipulations of a syntactic calculus somehow implemented in the brain. This does not seem to bode well for explaining how we learn to reason through interaction with the world around us. In this paper we will explore a notion of judgement derived from rich type theoretic approaches to semantics. We will claim that truth is supervenient on judgements 
that a situation is of a given type. We will argue for this on the basis of important classes of natural language examples where meaning is defined only in terms of subjective judgement and there is no objective truth of the matter, for example predicates of personal taste such as This soup is delicious, expressions of artistic judgement such as Stockhausen's Gruppen is a masterpiece and expressions of moral or political judgements such as Women should be allowed to drive. An important part of our approach has to do with the kind of reasoning that takes place during interaction in dialogue, and the notion of a dialogue gameboard as proposed by Ginzburg (2012) will play a significant part in the analysis.

\section{Predicates of personal taste and other judgements}

There is a considerable literature on exchanges involving predicates of personal taste such as (1).

A: This soup tastes great

B: No, it tastes horrible

Among much other work, the following have greatly influenced my own thinking about such examples: Björnsson and Almér (2011), Crespo and Fernández (2011), Lasersohn (2005), and Stojanovic (2007).

What proposition, if any, are $A$ and $B$ disagreeing about? If we adopt the analysis of dialogue proposed by Jonathan Ginzburg, most recently culminating in Ginzburg (2012), the following question arises: What, if anything, gets entered onto $A$ 's and $B$ 's dialogue gameboards as a commitment resulting from this exchange? A standard approach to these cases is to start from a notion of proposition defined in terms of truth in possible worlds and relativize this notion in some way to context possibly involving $A$ 's and $B$ 's beliefs.

It seems clear at least that $A$ and $B$ are not agreeing, as shown by (2).

(2) a. A: This soup tastes great

B: \#No, I agree, it tastes horrible

b. A: This soup tastes great

B: \#You're right, it tastes horrible

We might even go so far as to say that they are disagreeing, at least when we consider the acceptable dialogues in (3).

(3) a. A: This soup tastes great

B: No, I disagree, it tastes horrible

b. A: This soup tastes great

B: ?You're wrong, it tastes horrible 
The dialogue (3b) may be somewhat less acceptable, and this may be evidence that disagreement is not always about a simple matter of truth. In the literature on predicates of personal taste this kind of disagreement has been referred to as "Faultless disagreement", that is, disagreeing with somebody on a matter does not necessarily mean that you think they are wrong. There is a clear distinction, for example, between (3b), where how good the soup tastes is intuitively a matter of opinion and (4), where there is intuitively an objective fact of the matter as to whether the soup contains milk.

A: This soup contains milk

B: No, you're wrong, it's coconut milk

When it comes to moral and political judgements and even artistic judgements, issues of right and wrong can arise even if there is perhaps no objective fact of the matter.

(5) a. A: Women should not be allowed to drive

B: No, you're wrong, of course they should

b. A: Stockhausen's Gruppen is rubbish

B: No, you're wrong, it's a masterpiece

(5b) is particularly appropriate if $B$ feels that $A$ is ignorant about contemporary music and has no right to venture an uninformed opinion.

\section{Strategies for accommodating personal judgements into truth-based semantics}

The central question for a truth-based semantics is what $A$ and $B$ in our examples are disagreeing about. Can we find an appropriate proposition that they believe to be true and false respectively? Or can we interpret the personal judgement sentences in a way so that no conflict arises in order to account for the faultless aspect of the disagreement? One way to try to account for the no fault aspect is to say that the personal judgements express attitude reports. This might be realized by saying that (6a) actually expresses (6b).

(6) a. This soup tastes great

b. I think this soup tastes great

Initially, this seems like a plausible idea. However, if the two sentences were equivalent we would accept both of the dialogues in (7) to be equally acceptable

(7) a. A: This soup tastes great

B: ?\#You're entitled to your opinion, of course, but it tastes horrible

b. A: This soup tastes great

B: You're entitled to your opinion, of course, but I think it tastes horrible 
A theory which regards the two sentences in (6) as equivalent would have to explain why they are not substitutable for each other in (7).

A different strategy is to try to exploit the indices that are used for evaluation in a traditional model-theoretic semantics, that is, possible world, time, speaker, hearer, and so on. An obvious place to start is with the speaker of the sentence. We might say that the truth of personal judgements is relativized to the speaker of the sentence. This is schematically represented in (8).

$$
\begin{aligned}
& \llbracket \text { This soup tastes great } \rrbracket \ldots, \mathrm{spA}, \ldots \neq \\
& \llbracket \text { This soup tastes great } \rrbracket \ldots, \mathrm{spB}, \ldots
\end{aligned}
$$

This approach would mean that personal judgements are treated as if they contain an implicit first person indexical and so one might expect them to behave similarly to sentences in which there is an overt first person indexical as in (9).

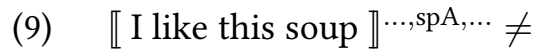

$\llbracket$ I like this soup $\rrbracket \cdots$, spB,$\ldots$

Unfortunately, however, the sentences with the overt indexical do not at all behave in the same way as personal judgements when it comes to disagreement, as shown in (10).
A: I like this soup
B: \#No, I don't /
No, you don't (you're just saying that) / I don't

The crucial point here is that you cannot say No, I don't in response to I like this soup whereas you can say No, it's not in response to This soup is delicious. Lasersohn (2005) makes a similar point.

It is not even clear that the interpretation of a personal judgement is always relative to the speaker. Consider the examples in (11).

(11) a. Child: This medicine's yucky

Parent: Yes, I know (it's yucky), but it will do you good

b. A: This soup tastes great

B: Does it? (I'm glad / It's horrible /

I can't tell what I think)

There's something more complex than straightforward indexical semantics going on. In (11a) the parent is adopting the perspective of the child. The parent can make this contribution even if the medicine tastes perfectly OK for them as an adult. Similarly (11b) seems to show that a question about a personal judgement most naturally addresses the personal judgement of the hearer, not the speaker. Similarly, the continuation I'm glad in this example seems to concern $A$ 's judgement of the soup, not $B$ 's, 
whereas It's horrible concerns B's judgement. There seems to be a notion of perspective here similar to the interpretation of spatial expressions like left and right where we can choose to adopt either our own or another person's perspective. It is different to the spatial case, however, in that with left and right, once you have fixed a perspective there does appear to be an objective fact of the matter whether one object is to the left or right of another. In the case of taste there does not appear to be a neutral "fact" independent of the perspective. Again Lasersohn (2005) has different examples making a similar point.

\section{Judgement and truth}

In mainstream semantics truth is central to our explanation of meaning and reasoning. Traditional notions of proposition are based on truth, for example truth in possible worlds. Propositions are regarded as sets of worlds where the proposition is true. In general, the approach to dealing with taste in the literature has been to refine this truth-theoretic approach by adding additional parameters (making truth relative or contextually determined). This has the consequence that ultimately there is some fact of the matter that is true, false or perhaps undefined if we allow truth-value gaps.

In type theory of the kind discussed in Martin-Löf (1984) and Nordström et al. (1990) we get a slightly different spin on this issue. A central notion is that of a judgement that an object $a$ is of a type $T, a: T$. We say " $a$ is of type $T$ " or " $a$ is a witness for $T$ ". There is, of course, a notion of truth in this kind of type theory but it is parasitic on judgement. Types are seen as the truth-bearers (following the dictum of "propositions as types") and types are "true" just in case there is something of the type. This means that types have a dual role: classifying objects and situations on the one hand and serving as truth bearers on the other (corresponding to propositions that there are objects or situations of a given type).

This suggests to us the following strategy for dealing with personal judgements: rather than taking truth as basic and trying to finagle judgement, we take judgement as basic and say that in many cases, though not all, there is, in addition, a fact of the matter. In a general sense, this is a Montagovian strategy: make the apparently more complex case basic and add to it for what you think of as being the ordinary case (cf. Montague's treatment of intensional verbs). Our claim is that we only think of taste predicates as being difficult because we are starting from truth-based semantics rather than judgement-based semantics.

Note that we are not saying that truth is not important for semantics. It is still of central importance. Our access to truth in natural (human) reasoning, however, is through judgement and it should not be surprising that this should be reflected in the nature of natural reasoning systems. 


\section{$5 \quad$ Type theory and personal judgements}

We shall make our proposal in terms of a type theory which we have called TTR, for "Type Theory with Records" (Cooper 2005a; Cooper 2005b; Cooper 2012; Cooper and Ginzburg 2015; Cooper in prep.).

We can think of a judgement as a type act in the sense of Cooper (2014). That is, we can be explicit about the role of an agent in the act of judgement: agent $A$ judges object $a$ to be of type $T, a::_{A} T$. Following a suggestion by Ginzburg (2012) we say that the result of a judgement that a situation $s$ is of type $T, s: T$, can be seen as a typetheoretic object, an Austinian proposition, a record with two fields, labelled 'situation' and 'type' as given in (12).

$$
\left[\begin{array}{ll}
\text { situation } & = \\
\text { type } & =
\end{array}\right]
$$

The Austinian proposition (12) is true just in case $s$ is indeed of type $T$. Now let us consider an Austinian proposition where we make the agent explicit. It has an additional field labelled 'agent'.

$$
\left[\begin{array}{ll}
\text { situation } & =s \\
\text { type } & =T \\
\text { agent } & =A
\end{array}\right]
$$

We call this a subjective Austinian proposition. It is true just in case $A$ judges $s$ to be of type $T, s: A T$. We will call Austinian propositions which have two fields as in (12) objective Austinian propositions. As type-theoretic objects these records belong to types. The type AusProp of Austinian propositions is (14).

$$
\left[\begin{array}{lll}
\text { situation } & : & \text { Sit } \\
\text { type } & : & \text { Type }
\end{array}\right]
$$

A record of this type is required to have two fields labelled 'situation' and 'type' and the objects in those fields must be respectively of type Sit ("situation") and Type (the type of types ${ }^{1}$ ). A record with additional fields also belongs to this type. Thus both objective and subjective Austinian propositions are of this type. The type SubjAusProp ("subjective Austinian proposition") in addition requires the agent field filled by an object of type Ind ("individual"). This is given in (15).

$$
\left[\begin{array}{lll}
\text { situation } & : & \text { Sit } \\
\text { type } & : & \text { Type } \\
\text { agent } & : & \text { Ind }
\end{array}\right]
$$

1 We avoid Russell's paradox by stratifying the types. See Cooper (in prep. 2012) for discussion. 
Thus while the records themselves have a fixed finite number of fields, the record types do not fully specify how many fields the records of that type should have. The records of a given type must have at least as many fields as specified in the type but they may have more. Thus the records we are using to model objective propositions will have two fields (for a situation and a type), whereas those which model subjective propositions have three fields (that is, with an additional field for the agent). However, the type that requires two fields (for a situation and a type) will have witnesses which have exactly the two fields as required, but it will also have witnesses with additional fields. Thus both objective and subjective propositions will be witnesses for the type which requires two fields. This means that the record types introduce a kind of underspecification even though the witnesses for those types are fully determinate with respect to the number of fields that they have.

Record types can be (partially) specified. That is, they can require that a record of the type not only contain appropriate fields with objects of the required type but also that they contain a particular object of the required type. An example is given in (16).

$$
\left[\begin{array}{lll}
\text { situation } & : & \text { Sit } \\
\text { type=soup-is-good } & : & \text { Type } \\
\text { agent } & : & \text { Ind }
\end{array}\right]
$$

Here we have used soup-is-good as a representation of the type corresponding to an utterance of This soup is good. We are not interested in the exact nature of this type in this paper. (16) is then a partially specified type of subjective propositions.

Our proposal is that in dialogical negotiation we are jointly reasoning about such types of propositions and that these are the objects which are entered into shared commitments on dialogue participants' gameboards, that is, the view of the common ground so far established in the dialogue according to the particular dialogue participant. (One may think of the types as doing the duty of "underspecified representations" of propositions.) Saying This soup is good offers the type (17a) or (17b) and claims you can instantiate it with a true proposition.
a. $\left[\begin{array}{lll}\text { situation } & : & \text { Sit } \\ \text { type=soup-is-good } & : & \text { Type } \\ \text { agent } & : & \text { Ind }\end{array}\right]$
b. $\left[\begin{array}{lll}\text { situation } & : & \text { Sit } \\ \text { type=soup-is-good } & : & \text { Type }\end{array}\right]$

Crucially, we think that it is not determined by the utterance whether the speaker has a subjective or objective proposition in mind and that often subjective opinion is offered or interpreted as objective fact. Answering yes (agreeing) means you can 
also instantiate it with a true proposition. Answering no (disagreeing) means you can instantiate a type with an incompatible type-field (e.g. soup-is-horrible). ${ }^{2}$

Gricean dialogue principles govern which individuals you are allowed to instantiate in the agent field in a subjective Austinian proposition. The maxim of quality says that you are only allowed to claim propositions are true if you have evidence. In the simplest case you are only allowed to assert subjective propositions in which you yourself are the agent. However, this flips to the audience in the case of a question such as Is the soup good? since the agent giving the answer must obey the maxim of quality and can only instantiate the agent with themselves.

However, this restriction on instantiation only holds in the simplest case. When your dialogue partner has already told you how they feel, then you have evidence for a proposition with them as agent. In such a case you can choose yourself or your dialogue partner as the agent, as illustrated in (18).
A: This medicine tastes yucky
B: No, it doesn't / Yes, I know

Actually, I think both of $B$ 's responses are ambiguous as to whether the agent of the judgement is $A$ or $B$ as illustrated by the continuations in (19).

(19) a. No, it doesn't. You're just pretending.

b. No, it doesn't. I think it's delicious.

c. Yes, I know. It's very bitter for young children.

d. Yes, I know. It's dreadfully bitter.

\section{Propositional attitudes towards subjective and objective propositions}

There are some cases in which it is unclear whether there is an objective fact of the matter or not. Consider (20).
A: (taking a sip of tea) This milk is sour
B: (tasting the milk) No, it's fine

Is there an objective fact concerning whether the milk is sour or not? The dialogue does not seem to force us into a decision. It is therefore fortunate that we have the record type (21), which does not decide the matter.

$$
\left[\begin{array}{lll}
\text { situation } & : & \text { Sit } \\
\text { type=milk-is-sour } & : & \text { Type }
\end{array}\right]
$$

2 To say that two types are incompatible means that there can be no object which is of both types. See the discussion of negation in Cooper and Ginzburg (2012). 
A record, $r$, is of a given record type, $T$, just in case $r$ has fields with labels which are the same as the labels in $T$ and objects in those fields which are of the types specified in the respective fields in $T$. Crucially, $r$ may also have additional fields with labels not in $T$. Thus an objective proposition not containing an agent could be of the type (21), but so also could a subjective proposition which in addition specifies an agent. Thus (21) does not specify whether the proposition is subjective or not. One suspects that there are many dialogues where it is unspecified as to whether we are dealing with objective facts or not, and this may lead to misunderstanding or even deliberate misinformation. This may have relevance for current political discourse.

It follows from this that any Austinian proposition of the type SubjAusProp, as defined in (15), will be of the type AusProp, as defined in (14), that is, SubjAusProp is a subtype of AusProp. The fact that we have a type of Austinian propositions in general and a type of subjective Austinian propositions but not a type of objective Austinian propositions gives us a prediction that predicates of propositional attitudes may select for either of the two types but not for objective propositions as such. In the remainder of this section we will look at some examples and discuss whether this prediction is borne out.

There are clearly verbs which select for subjective propositions but which do not allow objective propositions. Examples with English find are given in (22).

(22) a. Anne finds Mary beautiful (Sæbø 2009, p. 336)

b. \#Homer finds Bart gay (Sæbø 2009, p. 329)

There are similar examples with German finden 'find', as in (23).

(23) a. Ich finde, dass die Preise hoch sind

I find that the prices high are

'I find the prices high' (Sæbø 2009, p. 328, modified)

b. \#Die meisten Menschen finden, dass es einen Osterhasen gibt the most people find that it a Easter hare gives

'Most people find there to be an Easter Bunny' (Sæbø 2009, p. 328, modified)

Corresponding examples occur with Norwegian synes 'think/find', as shown in (24).

(24) a. Hun synes alle røykere er usympatiske

she thinks all smokers are unpleasant

'She thinks/finds that all smokers are unpleasant' (Sæbø 2009, p. 339)

b. \#Mange forskere synes at dinosaurene ble utryddet av et many researchers thinks that the dinosaurs were exterminated by a voldsomt kometnedslag

powerful comet strike

'Many researchers find that the dinosaurs were exterminated by a powerful comet strike' (Sæbø 2009, p. 335) 
Swedish tycka 'think/find' corresponds to Norwegian synes, as shown in (25).
a. Många tycker att kärnkraftverk
är vackra
many think that atomic power stations are beautiful
'Many people find atomic power stations beautiful' (Sæbø 2009, p. 328, modified)
b. \#Många forskare tycker att dinosaurierna blev utrotade av ett many researchers think that the dinosaurs were exterminated by a våldsamt kometnedslag powerful comet strike 'Many researchers find that the dinosaurs were exterminated by a powerful comet strike'

English think is a verb that clearly takes both subjective and objective propositions as complement, as shown in (26).

(26) a. Many people think that atomic power stations are beautiful

b. Many researchers think that the dinosaurs became extinct because of a gigantic comet striking the earth

Potential counterexamples for our prediction are those which appear to take only objective propositions as complements. A candidate is English believe as in (27).

(27) a. Many researchers believe that the dinosaurs became extinct because of a gigantic comet striking the earth

b. ?Many people believe this soup is delicious

Swedish tro 'believe' seems similar to English believe as shown in (28).

a. Många forskare tror att dinosaurierna blev utrotade av ett many researchers believe that the dinosaurs were exterminated by a våldsamt kometnedslag powerful comet strike 'Many researchers believe that the dinosaurs were exterminated by a powerful comet strike'

b. ?Många tror att denna soppa smakar utmärkt many believe that this soup tastes excellent 'Many people believe that this soup tastes excellent'

However, this data concerning believe/tro is a little misleading. While they appear to select for objective propositions they can in fact also occur with subjective propositions. It is just that when they do so, they induce an effect which is a little similar to 
switch reference: they require that the agent making the judgement in the subjective proposition in the complement is distinct from the subject of the embedding attitude verb. Thus (29) is something you can say when you have not yet tasted the soup but you have heard from somebody else that they thought it was good.

(29) I believe the soup is good

There are similar examples with Swedish tro as shown in (30).

(30) a. Vårt minne lurar oss att tro att människor med ett attraktivt yttre our memory tricks us to believe that people with an attractive exterior är trevligare än fula are nicer than ugly

'Our memory tricks us into believing that people with an attractive exterior are nicer than ugly people' (http://www.suntliv.nu/Amnen/Halsa/ Artiklar-om-halsa/Darfor-tror-vi-att-vackra-manniskor-ar-trevligare/, retrieved Oct. 29, 2012 )

b. Jag önskar att jag vore lika vacker som Sebastian tror att han I wish that I were as good looking as Sebastian believes that he $\ddot{a r}$ is

'I wish I were as good looking as Sebastian believes he is' (title of a novel by Christer Hermansson, 2003)

c. trots den pinsamma missen tror jag soppan var rätt så god in spite of the embarassing mistake believe I the soup was right so good ändå

anyway

'in spite of the embarassing mistake I believe the soup was pretty good anyway'

(http://tantgulsblogg.se/en-spicy-thai-soppa-och-tant-gul-tokar-till-det/, retrieved Oct 29, 2012)

In (30a) we believe that attractive people are generally judged to be nicer, not just that we think they are nicer. In (30b) Sebastian believes that other people find him goodlooking. Finally, in (30c) it is believed that the people to whom the soup was served judged it to taste good. In (31) we give a couple of constructed minimal pairs ${ }^{3}$ which further illustrate the point for Swedish.

(31) a. fag tror att medicinen smakar gott

I believe that the medicine tastes good

'I believe the medicine (will) taste(s) good'

3 These are based on examples offered by one of the reviewers. 
b. Fag tycker att medicinen smakar gott I think that the medicine tastes good 'I think the medicine tastes good'

c. Kim tror att små hundar är attraktiva Kim believes that small dogs are attractive 'Kim believes that small dogs are attractive'

d. Kim tycker att små hundar är attraktiva Kim thinks that small dogs are attractive 'Kim thinks that small dogs are attractive'

(31a) is something you might say to a child in order to persuade them to take the medicine. You may not have tasted the medicine yourself but you think the child will like it. (31b), on the other hand, means that you have tasted it yourself and your opinion is that it tastes good. You may also use this to persuade the child to take the medicine but here the argument would be "I think it's good, therefore you will think it's good". The sentence only expresses the antecedent in this argument. (31c) can be used to express that Kim believes that people find small dogs attractive, that is, people in general, possibly including Kim, though not necessarily. Think of a situation where Kim is opening a pet shop and wondering what animals to sell - Kim may not personally find small dogs attractive. (31d), on the other hand, requires that Kim personally finds small dogs attractive and cannot be used to say anything about the view of people in general (beyond, possibly, the unexpressed suggestion that if Kim finds small dogs attractive then other people will too).

If English believe/think make a similar distinction in terms of subjectivity with respect to their complement as Swedish tro/tycka, why do the latter seem so exotic and difficult for English speakers of Swedish? I believe that the reason for this is that the two pairs divide up the space of possibilities slightly differently. In Table 1, ' + ' means that the verb takes a subjective/objective complement, '-' means that it does not, and 'sr' means that the verb has the switch reference-like effect on the complement discussed above.

\begin{tabular}{|l|c|c|}
\hline & subjective & objective \\
\hline believe & $\mathrm{sr}$ & + \\
\hline think & + & + \\
\hline
\end{tabular}

\begin{tabular}{|l|c|c|}
\hline & subjective & objective \\
\hline tro & sr & + \\
\hline tycka & + & - \\
\hline
\end{tabular}

Table 1: The space of possibilities for the English and Swedish verbs

The fact that tycka does not take objective propositions as complement whereas think does is apparently enough to cause confusion among English non-native speakers of Swedish. 


\section{Conclusion}

We have argued that natural human reasoning is judgement based rather than truth based and that truth is parasitic on judgement. This seems a reasonable conclusion for agents whose access to truth is through judgement (their own or somebody else's). By this we do not wish to say that there is no notion of objective truth in natural reasoning. We suggest, however, that there are subjective judgements illustrated in natural language by a variety of personal judgements involving taste, morality and artistic judgement among other things, for which there is no objective fact of the matter. As natural reasoners, humans seem deeply engaged in discussing such judgements. They are simply interested in the judgements that other people make.

The distinction between subjective and objective propositions in our particular typetheoretic formulation results in two types of propositions: propositions in general which may or may not specify an agent making the judgement, and a subtype of this type for subjective propositions which do require an agent as the judge. We test the hypothesis that these two types can be selected for by predicates of propositional attitude, but that there is no predicate which can select for only objective propositions (since no such type is available according to our analysis). We have argued against some expected counterexamples to this claim.

\section{Acknowledgements}

This paper is for Helge Dyvik, a scholar of judgement, taste and closely related Germanic languages.

I am grateful to Elisabet Engdahl for discussion and to two anonymous reviewers for helpful comments. This research was supported in part by VR project 20091569, Semantic analysis of interaction and coordination in dialogue (SAICD) and VR project 2013-4873, Networks and Types (Nettypes). Previous versions of parts of this paper have been presented at the workshop Dialogue with Contextualism, Université Paris-Diderot, Sept. 18, 2012; at King's College, London, Oct. 18, 2012; at Trinity College Dublin, Feb. 15, 2013; at the 25th Scandinavian Conference of Linguistics, Reykjavík, May, 13-15, 2013; and at the Conference on Computing Natural Reasoning (CoCoNat'15), July 19-20, 2015, Indiana University, Bloomington.

\section{References}

Björnsson, Gunnar and Alexander Almér (2011). “The Pragmatics of Insensitive Assessments". In: The Baltic International Yearbook of Cognition, Logic and Communication 6, pp. 1-45.

Cooper, Robin (in prep.). "Type theory and language: from perception to linguistic communication”. Draft of book chapters available from https://sites.google.com/ site/typetheorywithrecords/drafts. 
Cooper, Robin (2005a). "Austinian truth, attitudes and type theory". In: Research on Language and Computation 3, pp. 333-362.

- (2005b). "Records and Record Types in Semantic Theory". In: Journal of Logic and Computation 15.2, pp. 99-112.

- (2012). "Type Theory and Semantics in Flux". In: Handbook of the Philosophy of Science. Ed. by Ruth Kempson, Nicholas Asher, and Tim Fernando. Vol. 14: Philosophy of Linguistics. General editors: Dov M. Gabbay, Paul Thagard and John Woods. Elsevier BV, pp. 271-323.

- (2014). "How to do things with types". In: Joint Proceedings of the Second Workshop on Natural Language and Computer Science (NLCS 2014) \& 1st International Workshop on Natural Language Services for Reasoners (NLSR 2014) fuly 17-18, 2014 Vienna, Austria. Ed. by Valeria de Paiva, Walther Neuper, Pedro Quaresma, Christian Retoré, Lawrence S. Moss, and Jordi Saludes. Center for Informatics and Systems of the University of Coimbra, pp. 149-158.

Cooper, Robin and Jonathan Ginzburg (2012). "Negative inquisitiveness and alternatives-based negation". In: Logic, Language and Meaning: 18th Amsterdam Colloquium, Amsterdam, The Netherlands, December 19-21, 2011, Revised Selected Papers. Ed. by Maria Aloni, Vadim Kimmelman, Floris Roelofsen, Galit W. Sassoon, Katrin Schulz, and Matthijs Westera. Lecture Notes in Computer Science 7218. Springer, pp. 32-41.

- (2015). “Type Theory with Records for Natural Language Semantics”. In: The Handbook of Contemporary Semantic Theory. Ed. by Shalom Lappin and Chris Fox. second. Wiley-Blackwell, pp. 375-407.

Crespo, Inés and Raquel Fernández (2011). "Expressing Taste in Dialogue”. In: SemDial 2011 (Los Angelogue): Proceedings of the 15th Workshop on the Semantics and Pragmatics of Dialogue. Ed. by Ron Artstein, Mark Core, David DeVault, Kallirroi Georgila, Elsi Kaiser, and Amanda Stent, pp. 84-93.

Ginzburg, Jonathan (2012). The Interactive Stance: Meaning for Conversation. Oxford: Oxford University Press.

Lasersohn, Peter (2005). "Context Dependence, Disagreement, and Predicates of Personal Taste". In: Linguistics and Philosophy 28, pp. 643-686.

Martin-Löf, Per (1984). Intuitionistic Type Theory. Naples: Bibliopolis.

Nordström, Bengt, Kent Petersson, and Jan M. Smith (1990). Programming in MartinLöf's Type Theory. Vol. 7. International Series of Monographs on Computer Science. Oxford: Clarendon Press.

Sæbø, Kjell Johan (2009). “Judgment ascription”. In: Linguistics and Philosophy 32, pp. 327-352. DoI: 10.1007/s10988-009-9063-4.

Stojanovic, Isidora (2007). "Talking about taste: disagreement, implicit arguments, and relative truth". In: Linguistics and Philosophy 30.6, pp. 691-706. 